\title{
Platelet-rich plasma versus corticosteroid injection for treatment of trigger finger: study protocol for a prospective randomized triple-blind placebo-controlled trial
}

Samuli Aspinen ${ }^{1 * \dagger}$ (D), Panu H. Nordback ${ }^{1 \dagger}$, Turkka Anttila', Susanna Stjernberg-Salmela ${ }^{1}$, Jorma Ryhänen ${ }^{1}$ and Jussi Kosola ${ }^{2}$

\begin{abstract}
Background: Trigger finger is a common hand disorder that limits finger range of motion and causes pain and snapping of the affected finger. Trigger finger is caused by an imbalance of the tendon sheath and the flexor tendon. The initial treatment is generally a local corticosteroid injection around the first annular (A1) pulley. However, it is not unusual that surgical release of the A1 pulley is required. Moreover, adverse events after local corticosteroid injection or operative treatment may occur. Platelet-rich plasma (PRP) has been shown to be safe and to reduce symptoms in different tendon pathologies, such as DeQuervain's disease. However, the effects of PRP on trigger finger have not been studied. The aim of this single-center triple-blind randomized controlled trial is to study whether PRP is non-inferior to corticosteroid injection in treating trigger finger. The secondary outcome is to assess the safety and efficacy of PRP in comparison to placebo.

Methods: The trial is designed as a randomized, controlled, patient-, investigator-, and outcome assessor-blinded, single-center, three-armed 1:1:1 non-inferiority trial. The patients with clinical symptoms of trigger finger will be randomly assigned to treatment with PRP, corticosteroid, or normal saline injection. The primary outcome is Patient-Rated Wrist Evaluation and symptom resolution. Secondary outcomes include Quick-Disabilities of the Arm, Shoulder and Hand; pain; grip strength; finger active range of motion; and complications. Appropriate statistical methods will be applied.
\end{abstract}

Discussion: We present a novel RCT study design on the use of PRP for the treatment of trigger finger compared to corticosteroid and normal saline injection. The results of the trial will indicate if PRP is appropriate for the treatment of trigger finger.

Trial registration: ClinicalTrials.gov NCT04167098. Registered on November 18, 2019.

Keywords: Clinical trial, Platelet-rich plasma, Trigger finger, Trigger thumb, Stenosing tenosynovitis

\footnotetext{
* Correspondence: Samuli.aspinen@hus.fi

${ }^{\dagger}$ Samuli Aspinen and Panu Nordback share joint authorship as first author.

'Department of Hand Surgery, Helsinki University Hospital, Topeliuksenkatu 5, 00260 Helsinki, Finland

Full list of author information is available at the end of the article
}

(c) The Author(s). 2020 Open Access This article is licensed under a Creative Commons Attribution 4.0 International License, which permits use, sharing, adaptation, distribution and reproduction in any medium or format, as long as you give appropriate credit to the original author(s) and the source, provide a link to the Creative Commons licence, and indicate if changes were made. The images or other third party material in this article are included in the article's Creative Commons licence, unless indicated otherwise in a credit line to the material. If material is not included in the article's Creative Commons licence and your intended use is not permitted by statutory regulation or exceeds the permitted use, you will need to obtain permission directly from the copyright holder. To view a copy of this licence, visit http://creativecommons.org/licenses/by/4.0/. The Creative Commons Public Domain Dedication waiver (http://creativecommons.org/publicdomain/zero/1.0/) applies to the data made available in this article, unless otherwise stated in a credit line to the data. 


\section{Background}

Trigger finger (stenosing tenosynovitis, TF) is a condition of the tendons of the hand that causes triggering, snapping, or locking on flexion of the involved finger. TF can limit the range of motion of the affected finger and is frequently accompanied by pain in the palm of the hand [1]. TF is often considered under the category of "repetitive strain injury" [2]. The snapping of the finger is caused by the imbalance of the tendon sheath and the flexor tendon, or more precisely, thickening of the first annular pulley, the tendon, or both. Although known as tenosynovitis, no inflammatory changes have been observed in histologic studies [3]. While the condition has been recognized since 1850, the exact etiology of the condition remains unknown [4].

TF is a very common hand disorder with an incidence of approximately $3 \%$ in the general population [4]. The incidence increases to $10 \%$ among patients with diabetes [5]. Besides diabetes, gout, carpal tunnel syndrome, DeQuervain's and Dupyutren's disease, amyloidosis, and mucopolysaccharidosis are thought to be associated with TF [4]. TF occurs in women six times more frequently than men and is most common during the middle fifth to sixth decades of life. The ring finger is the most commonly affected finger [6].

Conservative treatment of TF is mainly based on corticosteroid injections around the tendon sheath, where it is hypothesized to decrease the tendon-sheath disproportion [7]. Nonsteroidal anti-inflammatory agents, massage, heat, ice, splinting, exercises, and stretches might also be considered as a conservative approach to relieve symptoms [8]. The short-term effect of a single corticosteroid injection has been evaluated to set between 60 and $92 \%$ [1], whereas the incidence of spontaneous recovery has been estimated to be as high as 20-29\% [3]. There are three previously published randomized controlled studies comparing corticosteroid and saline injections for primary TF [9-11], advocating the use of corticosteroid injection. The short-term symptom resolution of corticosteroid versus saline injection in these studies was $54-64 \%$ versus 15-27\%, respectively. While short-term results support the use of corticosteroid injection in primary TF, the efficacy seems to decrease over time and the long-term evidence is insufficient $[12,13]$.

If conservative treatment of TF fails or symptoms recur, and the patient is compliant, surgical release of the A1 pulley should be considered [14]. Surgical release of the pulley structure may be executed in an open, percutaneous, or endoscopic manner with uncertain comparative evidence; open release is the most used and traditional method [4].

Platelet-rich plasma (PRP) has been shown to reduce symptoms in different tendon pathologies [15, 16] and seems to be superior to cortisone [17-19]. PRP therapy is safe and feasible [20] but does not reverse the degenerative tendon changes [21]. On the other hand, cortisone treatment is not a long-term solution due to the relatively high recurrence rates after injections [22] and can cause adverse events in patients [23].

Considering the possible adverse events relating to open or percutaneous TF surgery [24], novel methods should also be considered. As PRP therapy seems to be safe and effective in many tendon pathologies, we designed a prospective placebo-controlled randomized trial to evaluate the possible benefits of PRP therapy in TF treatment. Our primary hypothesis is that PRP is noninferior to cortisone measured with symptom resolution and Patient-Rated Wrist Evaluation (PRWE). The secondary hypothesis of this trial is that single injection of PRP is superior compared to placebo in the treatment of TF.

\section{Methods/design}

\section{Trial hypothesis}

Our primary hypothesis is that PRP is non-inferior to cortisone, and the secondary hypothesis of this trial is that single injection of PRP is superior compared to placebo in the treatment of TF. The primary endpoint is the Patient Rated Wrist Evaluation (PRWE) score and symptom resolution at 6 months post-injection. This will also be the timepoint for unveiling the primary allocation. Secondary objectives include Quick-Disabilities of the Arm, Shoulder and Hand (Q-DASH); pain (Visual Analogue Scale, VAS); grip strength; active range of motion (ROM); rate of adverse events; and global improvement.

\section{Trial design}

The trial is designed as a randomized, controlled, patient-, investigator-, and outcome assessor-blinded, single-center, three-armed 1:1:1 non-inferiority trial. The CONSORT diagram of the trial cohort is presented in Fig. 1.

\section{Participant characteristics}

We will assess the eligibility of all patients with TF that are referred to Helsinki University Hospital. These participants will be screened according to the inclusion and exclusion criteria. A recruitment investigator (RI) will confirm the clinical diagnosis of TF. The diagnosis is based on the following clinical findings: tenderness/ pain over the flexor tendon sheath (A1 pulley), thickening or swelling of the tendon and/or the tendon sheath, and triggering or snapping of the affected finger. To qualify as a RI, all trial physicians must have experience of treating more than 200 cases of TF before the start of the trial.

Patients eligible for this trial will receive written information. The RI will obtain consent from the participants and collect baseline data prior to the randomization. The eligibility criteria are presented in Table 1. 


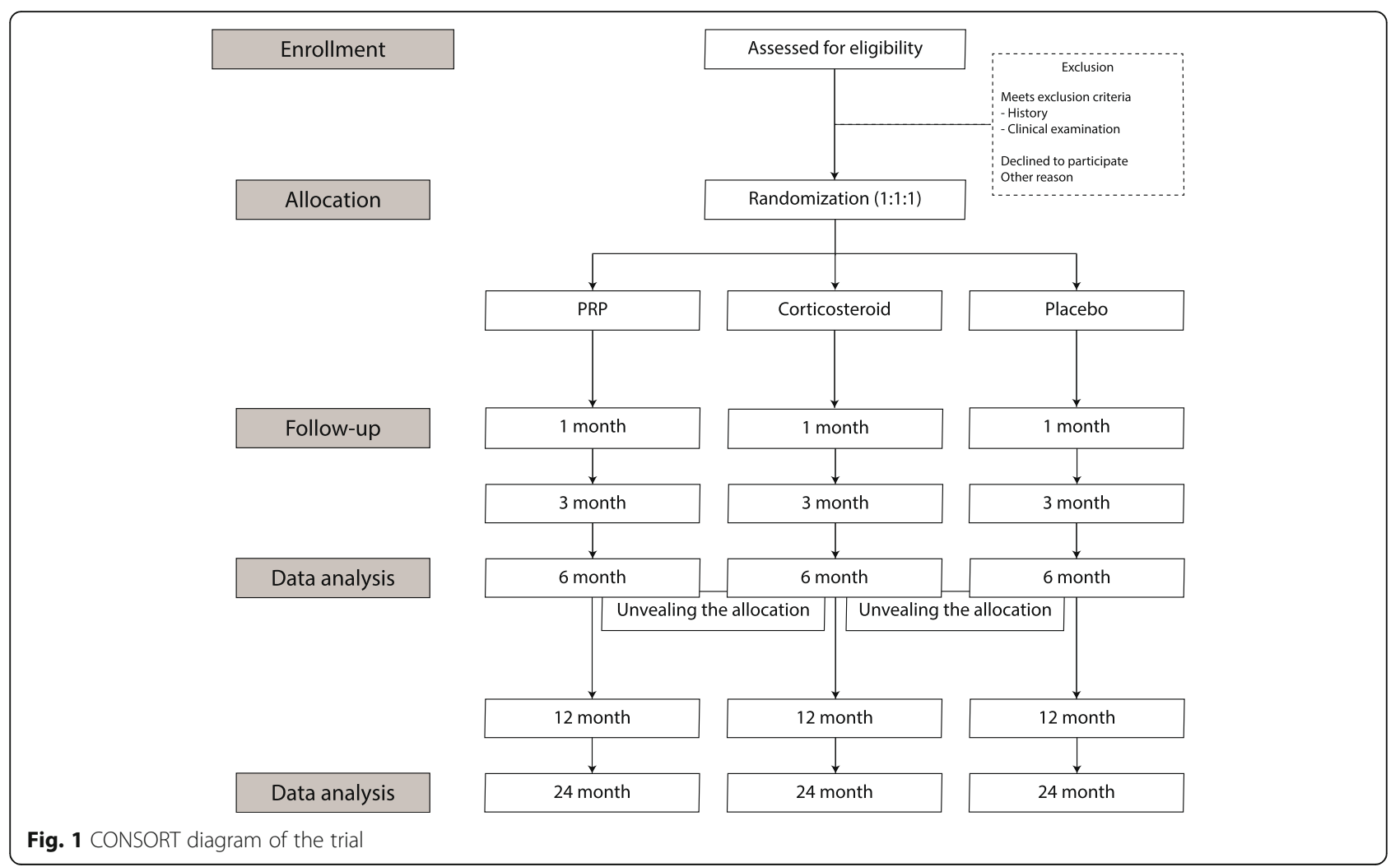

Participation in the trial is voluntary, and withdrawal is allowed at any time. In case of inadequate symptom relief after injection, the allocation will be unveiled. The patient will be offered either a corticosteroid injection (cross-over or second injection) or open surgery under local anesthesia, but preferably not before 6 months after the initial treatment.

\section{Preparation of PRP, corticosteroid, and placebo}

PRP is prepared according to the manufacturer's instructions (Regen Lab SA, Switzerland). Each voluntary patient eligible for the trial will have $10 \mathrm{ml}$ of fresh venous

Table 1 Trial eligibility criteria

\begin{tabular}{ll}
\hline $\begin{array}{l}\text { Inclusion criteria } \\
\text { (all of the following) }\end{array}$ & Exclusion criteria (any of the below) \\
\hline Age 18-75 & Diabetes \\
$\begin{array}{l}\text { Trigger finger in 1-2 rays } \\
\text { of the affected hand }\end{array}$ & $\begin{array}{l}\text { Trigger finger in }>2 \text { rays of affected } \\
\text { hand }\end{array}$ \\
$\begin{array}{l}\text { Symptom duration }>3 \\
\text { months }\end{array}$ & $\begin{array}{l}\text { Rheumatoid arthritis or other condition } \\
\text { requiring continuous oral corticosteroids } \\
\text { Previous history of surgery or injection in } \\
\text { the affected ray } \\
\text { Dupuytren's disease of the affected } \\
\text { hand } \\
\text { Alcohol or drug abuse } \\
\text { Mental instability }\end{array}$ \\
\hline
\end{tabular}

blood withdrawn in a sterile manner into PRP tubes by a research nurse to ensure blinding of the treatment. The nurse will then move to another room, randomize the patient, and prepare the product indicated by the randomization. After centrifugation, $0.5 \mathrm{ml}$ of readymade PRP will be used. The corticosteroid group will receive $0.5 \mathrm{ml}$ of Depo-medrol, and the control group will receive $0.5 \mathrm{ml}$ of $0.9 \%$ saline. The syringe used will be taped by the nurse with sterile opaque tape and provided to the investigator. To ensure concealment, the research nurse will not participate further in the treatment or follow-up of the patients.

\section{Randomization and concealment}

A randomization sequence will be generated by an independent investigator (JK) not involving in the execution of the trial using an internet-based program (sealedenvelope.com). Patients will be allocated to one of the three treatment groups in a 1:1:1 ratio using permuted block randomization with variable block size. The randomization will be performed by the research nurse by opening a sequentially numbered sealed opaque envelope after the RI has confirmed the eligibility and the voluntary participance of the patient. The envelopes will be kept in a secure, lockable cabinet that is only accessible by the study nurse. Neither the patient nor the RI will know the treatment product indicated by the randomization. 


\section{Interventions}

All injections will be administered by a trained hand surgeon (SS-S) or a hand surgeon in training (PN, SA, TA). Each of these physicians has the experience of treating more than 200 cases of TF before the start of the trial. The injection technique will be landmark based in each group.

Patients will be injected under aseptic conditions with a 23-gauge needle. During the injection, patients will be in a seated position with their wrists resting in supination on the table. The flexor tendon and the first annular pulley will be palpated. The needle will be introduced through the skin and into the supratendineous space at a slight oblique angle oriented distal to proximal. The patient will then be asked to flex and extend the finger; if the needle and the syringe hold still, the injection will be given. In this way, we will avoid accidental intratendinous injection.

Concomitant treatment with nonsteroidal antiinflammatory agents, massage, heat, ice, exercises, and stretches are permitted, whereas repeated injections and splinting are prohibited.

\section{Outcome measures}

The primary enpoints are PRWE and symptom resolution at 6 months post-injection. Secondary outcomes include Q-DASH, pain on Visual Analogue Scale (VAS, $0=$ no pain, $10=$ worst imaginable pain), grip strength, finger active range of motion (ROM), and global improvement. The possible recurrence of TF symptoms will be registered. After initial treatment, follow-up will take place at $1,3,6,12$, and 24 months post-treatment. The trial schedule of enrolment, interventions, assessments, and data collection is presented in Fig. 2.

\section{Patient-Rated Wrist Evaluation}

The Patient-Rated Wrist Evaluation (PRWE) is a simple standardized outcome measure for wrist and hand pathologies that is easy to administer and score in clinical practice. The PRWE is a 15-item questionnaire designed to measure pain and disability in activities of daily living [25]. The Finnish version has been translated, culturally adapted, and validated [26].

\section{Symptom resolution}

Symptom resolution is a consensus between the patient and doctor on the perceived benefit of the treatment and is rated as follows: $0=$ no response; $1=$ partial response, but not satisfactory, warranting further treatment; 2 = partial response, satisfactory, not warranting further treatment; and 3 =complete resolution of symptoms and signs.
Quick-disabilities of the Arm, Shoulder and Hand

The Quick-Disabilities of the Arm, Shoulder and Hand (Q-DASH) is a 11-item questionnaire that considers the upper extremity as one functional unit [27]. It is a widely used reference for self-reported disability in various pathologies that affect the upper limb. Similar to the PRWE, the Finnish version has been translated, culturally adapted, and validated [28].

\section{Pain}

The Visual Analogue Scale (VAS) consists of a straight line with endpoints that define extreme limits to experiencing pain, from "no pain at all" and "pain as bad as it could be" [29]. The subject is asked to mark their pain level on the line between the two endpoints. The distance between "no pain at all" and the mark defines the subject's pain. The VAS is a validated and reliable tool in pain assessment and is easy to use [30].

\section{Grip strength and finger range of motion}

Grip strength will be determined with a dynamometer (JAMAR hand dynamometer Model J00105, Lafayette, IN, 47903, USA). Finger active range of motion (ROM) will be measured using a manual goniometry. In addition to thumb interphalangeal joint goniometry, thumb active ROM is measured by using the Kapandji thumb opposition score (Fig. 3) [31].

\section{Global improvement}

Global improvement is a patient-centered standpoint of perceived benefit of the intervention. Global improvement is evaluated using five-step Likert scale from $(-2)$ "Much worse" to (+2) "Much better."

\section{Adverse events}

Complications will be reported. Tendon, nerve, arterial injury, chronic regional pain syndrome, infection, hematoma, or any other condition that can be attributed to the intervention will be regarded as adverse events (event needing intervention or not disappearing).

\section{Data collection, management, and statistical plan Data collection}

All RIs will be trained for trial electronic database use, injection technique, ROM, and grip measurements. For PRWE and Q-DASH questionnaires, forms on paper will be the primary data collection tools. When receiving the questionnaire forms, a trial nurse will make a visual check of the responses and queries for missing data when possible. Furthermore, the trial nurses will be educated on preparation of PRP, corticosteroid, and placebo. RIs will be blinded to group allocation and will store the forms in an electronic database by double data entry to minimize typing errors. Patient records will be reviewed 


\begin{tabular}{|c|c|c|c|c|c|c|c|c|c|}
\hline & \multicolumn{9}{|c|}{ STUDY PERIOD } \\
\hline & \multirow{2}{*}{$\begin{array}{c}\text { Enrolment } \\
\\
2 \text { weeks } \\
\text { prior } \\
\text { intervention }\end{array}$} & \multirow{2}{*}{$\begin{array}{c}\begin{array}{c}\text { Allocatio } \\
\mathbf{n}\end{array} \\
0 \\
0\end{array}$} & \multicolumn{6}{|c|}{ Post-allocation } & \multirow{2}{*}{ 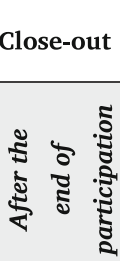 } \\
\hline TIMEPOINT & & & 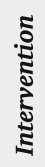 & 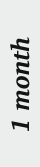 & 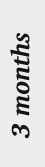 & & 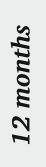 & 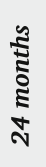 & \\
\hline \multicolumn{10}{|l|}{ ENROLMENT: } \\
\hline Eligibility screen & $\mathrm{X}$ & & & & & & & & \\
\hline Informed consent & $X$ & & & & & & & & \\
\hline Allocation & & $\mathrm{X}$ & & & & & & & \\
\hline \multicolumn{10}{|l|}{ INTERVENTIONS: } \\
\hline$P R P$ & & & $\mathrm{X}$ & & & & & & \\
\hline Corticosteroid & & & $\mathrm{X}$ & & & & & & \\
\hline Placebo & & & $\mathrm{X}$ & & & & & & \\
\hline \multicolumn{10}{|l|}{ ASSESSMENTS: } \\
\hline$P R W E$ & $\mathrm{X}$ & & & & $\mathrm{X}$ & $\mathrm{X}^{*}$ & $\mathrm{X}$ & $\mathrm{X}$ & \\
\hline Symptom resolution & & & & $\mathrm{X}$ & $\mathrm{X}$ & $\mathrm{X}^{*}$ & $\mathrm{X}$ & $\mathrm{X}$ & \\
\hline Q-DASH & $\mathrm{X}$ & & & & $\mathrm{X}$ & $\mathrm{X}$ & $\mathrm{X}$ & $\mathrm{X}$ & \\
\hline VAS & $X$ & & & $\mathrm{X}$ & $\mathrm{X}$ & $\mathrm{X}$ & $\mathrm{X}$ & $\mathrm{X}$ & \\
\hline Grip & $\mathrm{X}$ & & & & $\mathrm{X}$ & $\mathrm{X}$ & $\mathrm{X}$ & $\mathrm{X}$ & \\
\hline ROM & $\mathrm{X}$ & & & & $\mathrm{X}$ & $\mathrm{X}$ & $\mathrm{X}$ & $\mathrm{X}$ & \\
\hline Global improvement & & & & $\mathrm{X}$ & $\mathrm{X}$ & $\mathrm{X}$ & $\mathrm{X}$ & $\mathrm{X}$ & \\
\hline Complications & & & & & & & & & \\
\hline
\end{tabular}

Fig. 2 The schedule of enrolment, interventions, assessments, and data collection. PRP, platelet-rich plasma; PRWE, Patient-Rated Wrist Evaluation; Q-DASH, Quick-Disabilities of the Arm, Shoulder and Hand; ROM, finger active range of motion; VAS, Visual Analogue Scale. ${ }^{*}=$ primary endpoint of the study

when collecting missing data or interpreting inconsistent or implausible data.

\section{Data management and monitoring}

A database including patients' identification information and consent forms will be generated. This database will also include the identification code given to each patient and the intervention. Questionnaire forms on paper are the primary data collection tools for the study. As the questionnaire forms are received, a study nurse will make an inspection of the responses and inquire missing data when possible. Research assistant, blinded to the group allocation, will store the forms into a passwordprotected electronic database on a hospital-provided server by double data entry to minimize typing errors.

No separate data monitoring committee will be established. As collected outcome data is de-identified regarding trial group, the RIs and biostatistician can control for safety of the interventions during the trial without compromising concealment. An interim analysis of the de-identified data will be run after $40 \%$ of the patients are enrolled and followed for 6 months. If any concerns arise regarding trial safety, the concealment will be unveiled, and the trial will be discontinued. 


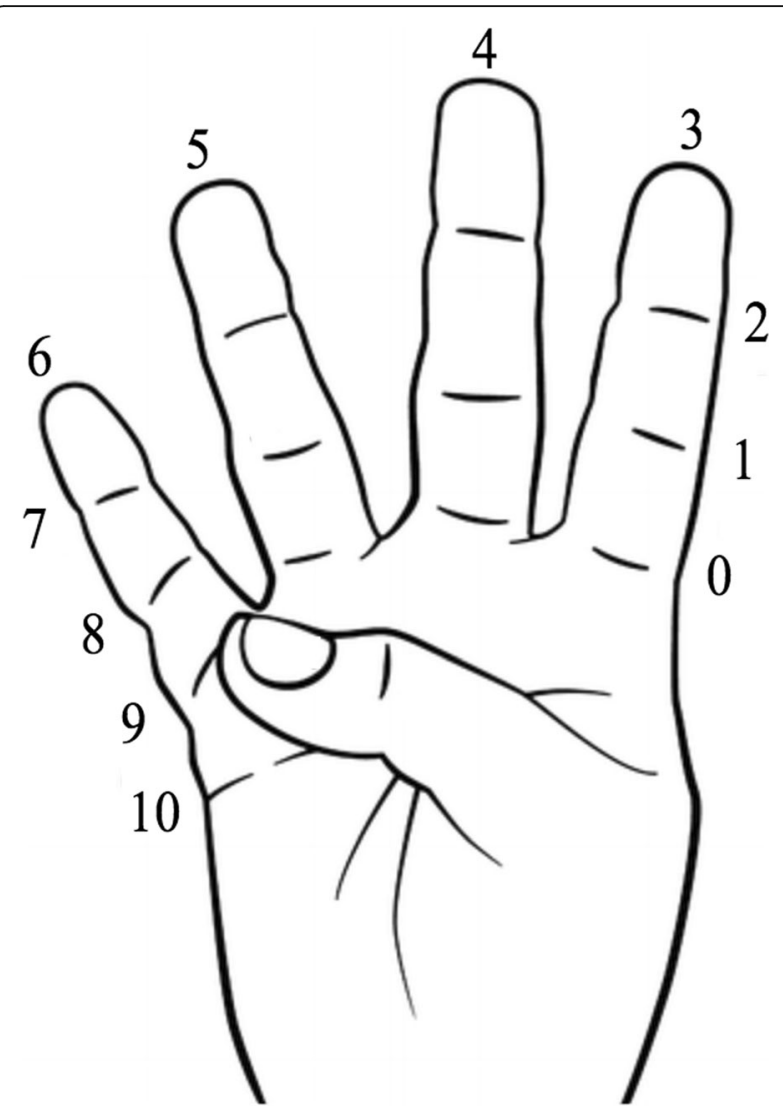

Fig. 3 Kapandji thumb opposition score $(0=$ no opposition, $10=$ maximal opposition

To ensure correct execution of the study, audits may be conducted if deemed necessary. However, routine audits are not planned.

\section{Sample size}

The primary outcome measure is PRWE, and the primary hypothesis of our trial is that single injection of PRP is non-inferior to single injection of corticosteroid in the treatment of TF measured with PRWE total score. The non-inferiority margin is set at 11.5 points using the PRWE minimally clinically important difference [32, 33]. To exclude the non-inferiority margin, the trial will require 32 patients in each group to observe MCID (non-inferiority margin 11.5, SD 14) in PRWE scores between the trial groups with a power of $90 \%$ and using a one-sided type I error rate of $2.5 \%$. We will recruit 117 patients to account for 20\% loss during follow-up.

\section{Statistical plan}

Statistical analysis will be performed with an intentionto-treat method. A statistical software program will be used for analyzing entered data (IBM SPSS Statistics for
Windows, Version 25.0. Armonk, NY: IBM Corp. 2017). Blinded data interpretation will be used to diminish interpretation bias; therefore, the biostatistician will be unaware of the group assignments when performing the analyses [34].

Descriptive statistics will be presented as mean (standard deviation) or median (interquartile range) for continuous variables and count (percent) for categorical variables. Levene's test will be used to examine the homogeneity of variance between groups, and Welch's or Student's $t$ test will be used to compare the point estimates for the means of the intervention groups. Ninetyfive percent confidence intervals will be calculated for the mean difference. Chi-square test or Fisher's exact test will be used to assess categorical data. Repeated measures will be analyzed using generalized linear mixed models.

The criterion for statistical significance will be set at $p=0.025$ (one-sided) or $p=0.05$ (two-sided). All $p$ values will be reported to three decimal places with those less than 0.001 reported as $p<0.001$.

\section{Cross-over, loss to follow-up, and missing data}

Participants enrolled will be allowed to call for unveiling the concealment at any point of the trial (preferably no sooner than 6 months post-randomization). However, to minimize this, the following will be addressed prior to trial enrolment to ensure that potential participants:

* Are willing to receive any of the interventions

* Understand that treatments might not provide benefit

* Are willing to remain with their allocation for 6 months

In case the allocation is unveiled, the patient will be offered either a corticosteroid injection (cross-over or second injection) or open surgery under local anesthesia based on the patients' preference.

We will document the number and proportion of patients eligible for and compliant with each follow-up. If the number of patients withdrawing from any arm of the trial is greater than the anticipated $20 \%$ at 6 months, an analysis of the demographic and prognostic characteristics will be performed between the individuals who withdraw and those who remain in the trial. Moreover, data may not be available due to voluntary withdrawal of patients, lack of completion of individual data items, or general loss to follow-up. Where possible, the reasons for missing data will be ascertained and reported. If judged appropriate, missing data will be imputed using MICE [35] and in concordance to the respective manuals of the questionnaires used. However, the main analysis will be done using the available (not the imputed) data. 


\section{Regulatory aspects}

Platelet-rich plasma is a biologic drug. However, it is not considered to be part of human cells, tissues, and cell- and tissue-based products (HCT/Ps, Title 21 United States Code of Federal Regulations Part 1271 (21 CFR 1271)). PRP is regulated by regulating the device used to manufacture it. In the case of PRP, the original predicate device is a platelet and plasma separator that produces PRP [36]. Likewise, Finnish Medicines Agency (FIMEA) does not consider PRP as a regulated drug, and thus, the approval for running this trial was not applied from FIMEA.

\section{Ethics and dissemination}

Corticosteroid injections are widely used and considered safe and effective in the conservative treatment of TF. PRP is prepared from autologous blood and is inherently safe. Any concerns associated with allografts or xenografts regarding transmission of diseases, such as human immunodeficiency virus or hepatitis, or triggering of immunogenic reactions are eliminated [37]. The placebo consists of $0.9 \%$ saline and is safe and appropriate [9-11].
The trial will be conducted according to the Declaration of Helsinki. The study was approved by the Helsinki and Uusimaa Hospital District Ethical Committee (reference number HUS/2845/2019). The protocol is registered with ClinicalTrials.gov (trial identifying number NCT04167098, Table 2). The trial protocol was developed according to the Standard Protocol Items: Recommendations for Interventional Trials (SPIRIT) statement. The findings of this trial will be disseminated through peer-reviewed publications and conference presentations.

\section{Discussion}

An increasing interest in biologic agents as nonoperative treatment modalities or to augment surgical procedures has been observed in recent years. One of these, PRP, has been shown to reduce symptoms in different tendon pathologies with the rationale to potentially accelerate the healing process [38].

PRP has positive effects on both short-term and longterm pain on tendon and ligament healing [39]. PRP contains various growth factors that have potential

Table 2 Content of the trial registry

\begin{tabular}{|c|c|}
\hline Data category & Information \\
\hline $\begin{array}{l}\text { Primary registry and trial identifying } \\
\text { number }\end{array}$ & ClinicalTrials.gov; NCT04167098 \\
\hline Date of registration in primary registry & November 18, 2019 \\
\hline Date and version identifier & October 9, 2020, version 1.2 \\
\hline Source(s) of monetary or material support & - \\
\hline Primary sponsor & Töölö Hospital \\
\hline Secondary sponsor & University of Helsinki \\
\hline Contact for public queries & Samuli Aspinen, +358406360546, samuli.aspinen@hus.fi \\
\hline Contact for scientific queries & Samuli Aspinen, +358406360546, samuli.aspinen@hus.fi \\
\hline Public title & Effectiveness of Platelet-rich Plasma for Treatment of Trigger Finger \\
\hline Scientific title & $\begin{array}{l}\text { A Prospective Randomized Placebo-controlled Trial Comparing Platelet-rich Plasma and Corticosteroid } \\
\text { Injection for Treatment of Trigger Finger }\end{array}$ \\
\hline Countries of recruitment & Finland \\
\hline Health condition(s) or problem(s) & Tendon entrapment \\
\hline Intervention(s) & $\begin{array}{l}\text { (1) PRP injection, } 0.5 \mathrm{ml} \text { platelet-rich plasma around A1 tendon sheath; (2) corticosteroid injection, } 0.5 \mathrm{ml} \\
\text { methylprednisolone around } \mathrm{A} 1 \text { tendon sheath; and (3) placebo injection, } 0.5 \mathrm{ml} 0.9 \% \text { saline around A1 } \\
\text { tendon sheath }\end{array}$ \\
\hline Key inclusion and exclusion criteria & $\begin{array}{l}\text { Inclusion: age } 18-75 \text {, trigger finger in } 1-2 \text { rays, symptom duration }>3 \text { months } \\
\text { Exclusion: diabetes, rheumatoid arthritis or other condition requiring continuous oral corticosteroids, }>2 \\
\text { affected rays, previous history of surgery or injection to the affected ray, alcohol or drug abuse, mental } \\
\text { instability }\end{array}$ \\
\hline Study type & Interventional \\
\hline Date of first enrolment & April 9, 2020 \\
\hline Target sample size & 117 \\
\hline Recruitment status & Recruiting \\
\hline Primary outcome(s) & Symptom resolution (rate of success), Patient-Rated Wrist Evaluation \\
\hline Key secondary outcomes & $\begin{array}{l}\text { Quick-Disabilities of the Arm, Shoulder and Hand; pain (Visual Analogue Scale); global improvement; grip } \\
\text { strength; finger range of motion (ROM); complications }\end{array}$ \\
\hline
\end{tabular}


tendon-healing properties [38]. PRP has been previously used in hand pathologies such as osteoarthrosis [40]. Furthermore, Ramesh et al. [41] reported a 77\% success rate after one and a 93\% success rate after two doses of autologous PRP for the treatment of DeQuervain's disease. The effects of PRP on TF have not yet been studied.

Digital stenosing tenosynovitis (i.e., TF) is a common example of a tendon pathology caused by the imbalance of the flexor and its sheath. Injection of corticosteroids in the vicinity of the A1 pulley is generally accepted as a first-line therapy, although recurrence rates up to $33 \%$ have been reported [1]. Moreover, up to $5.8 \%$ of major adverse events have been reported in soft-tissue injections of cortisone (defined as those needing intervention or not disappearing) [23]. As some authors have stated superiority of PRP compared to cortisone in select musculoskeletal disorders [17-19], investigating the clinical efficacy of PRP in treating TF is warranted.

Despite the increasing interest and use of PRP in clinical orthopedics, there are still concerns regarding its clinical efficacy due the lack of high-quality randomized controlled trials. Contradictory results have also been observed. A participant-, investigator-, and assessorblinded, placebo-controlled, randomized trial setting is the reference standard in trial designs. Thus, we conceived this trial to assess the effectiveness of PRP intervention in treating TF of the digits in a high-quality trial setting by measuring patient-rated outcomes, symptom reduction, and improvement of function. Moreover, to the best of our knowledge, this study is the first clinical trial to assess the use of PRP in TF.

\section{Limitations}

The main limitation of the study will be the use of nonstandardized PRP preparations. The number of platelets in a batch of PRP cannot be determined during the procedure, and controlling the concentration of platelets and leukocytes in a given batch of PRP is difficult [42]. Thus, we decided to use a pragmatic approach to PRP intervention that simulates the genuine clinical setting in which PRP is most commonly administered.

\section{Trial status}

The recruitment phase of the trial has started. The first participant was randomly assigned on 9 April 2020. Recruitment is expected to be completed by December 2021. This protocol is version 1.2, dated 9 October 2020 . Trial completion is expected by December 2023.

\section{Abbreviations}

PRP: Platelet-rich plasma: PRWE: Patient-Rated Wrist Evaluation; QDASH: Quick-Disabilities of the Arm, Shoulder and Hand; RI: Recruitment investigator; ROM: Finger active range of motion; TF: Trigger finger; VAS: Visual Analogue Scale

\section{Acknowledgements}

We would like to thank Mr. Timo Pessi for his expertise in revising the statistical plan for this study.

\section{Authors' contributions}

SA and JK conceived the trial. All authors participated in the design of the trial. PN, SA, and JK drafted the manuscript. All authors contributed to the refinement of the trial protocol and approved the final manuscript.

\section{Funding}

The trial is funded by Helsinki University Hospital institutional funding and a grant received from the Finnish Society for Surgery of the Hand. No external funding from medical industry will be used. The funders will not have any role in the collection, management, analysis, and interpretation of data; the writing of the report; and the decision to submit the report for publication.

Availability of data and materials

The datasets generated and analyzed during this trial will be available from the corresponding author on reasonable request.

\section{Ethics approval and consent to participate}

The trial will be conducted according to the Declaration of Helsinki, and the trial protocol, the consent form, and related documents were reviewed and approved by the Helsinki and Uusimaa Hospital District Ethical Committee (reference number: HUS/2845/2019). Any protocol amendments will be reported and submitted to the Ethics Committee. Written informed consent to participate will be obtained from all participants. Anonymity and confidentiality of participants will be ensured, and the trial adheres to EU General Data Protection Regulation. All participants will be assured that the trial is voluntary, and withdrawal is allowed at any point. Any unexpected harm caused to patients who are enrolled into the study and that are attributable to the study interventions/assessments will be covered by the insurance of the Helsinki University Hospital.

\section{Consent for publication}

Not applicable.

\section{Competing interests}

The authors declare that they have no competing interests.

\section{Author details}

${ }^{1}$ Department of Hand Surgery, Helsinki University Hospital, Topeliuksenkatu 5, 00260 Helsinki, Finland. ²Department of Orthopaedics and Traumatology, Kanta-Häme Central Hospital, Ahvenistontie 20, 13530 Hämeenlinna, Finland.

Received: 6 April 2020 Accepted: 16 November 2020

Published online: 27 November 2020

\section{References}

1. Peters-Veluthamaningal C, van der Windt DA, Winters JC, Meyboom-de Jong B. Corticosteroid injection for trigger finger in adults. Cochrane Database Syst Rev. 2009;(1):CD005617.

2. Gorsche R, Wiley JP, Renger R, Brant R, Gemer TY, Sasyniuk TM. Prevalence and incidence of stenosing flexor tenosynovitis (trigger finger) in a meatpacking plant. J Occup Environ Med. 1998;40:556-60

3. Moore JS. Flexor tendon entrapment of the digits (trigger finger and trigger thumb). J Occup Environ Med. 2000;42:526-45.

4. Fiorini HJ, Tamaoki MJ, Lenza M, Gomes Dos Santos JB, Faloppa F, Belloti JC. Surgery for trigger finger. Cochrane Database Syst Rev. 201820;2(2): CD009860.

5. Stahl S, Kanter $Y$, Karnielli E. Outcome of trigger finger treatment in diabetes. J Diabetes Complicat. 1997;11:287-90.

6. Makkouk AH, Oetgen ME, Swigart CR, Dodds SD. Trigger finger: etiology, evaluation, and treatment. Curr Rev Musculoskelet Med. 2007;1:92-6.

7. Blood TD, Morrell NT, Weiss AP. Tenosynovitis of the hand and wrist: a critical analysis review. JBJS Rev. 2016;29:4.

8. Matthews A, Smith K, Read L, Nicholas J, Schmidt E. Trigger finger: an overview of the treatment options. JAAPA. 2019;32:17-21. 
9. Lambert MA, Morton RJ, Sloan JP. Controlled study of the use of local steroid injection in the treatment of trigger finger and thumb. J Hand Surg Br. 1992;17:69-70.

10. Murphy D, Failla JM, Koniuch MP. Steroid versus placebo injection for trigger finger. J Hand Surg Am. 1995;20:628-31.

11. Peters-Veluthamaningal C, Winters JC, Groenier KH, Jong BM-D. Corticosteroid injections effective for trigger finger in adults in general practice: a double-blinded randomised placebo controlled trial. Ann Rheumatic Dis. 2007;67:1262-6.

12. Huisstede BM, Gladdines S, Manon S, Randsdorp MS, Koes BW. Effectiveness of conservative, surgical, and postsurgical interventions for trigger finger, Dupuytren disease, and De Quervain disease: a systematic review. Arch Phys Med Rehabil. 2018;99:1635-49.

13. Ma S, Wang C, Li J, Zhang Z, Yu Y, Lv F. Efficacy of corticosteroid injection for treatment of trigger finger: a meta-analysis of randomized controlled trials. J Investig Surg. 2019;32:433-41.

14. Amirfeyz R, McNinch R, Watts A, Rodrigues J, Davis TRC, Glassey N, Bullock J. Evidence-based management of adult trigger digits. J Hand Surg Eur Vol. 2017:42:473-80.

15. Fitzpatrick J, Bulsara M, Zheng MH. The effectiveness of platelet-rich plasma in the treatment of tendinopathy: a meta-analysis of randomized controlled clinical trials. Am J Sports Med. 2016;45:226-33.

16. Barile A, La Marra A, Arrigoni F, Mariani S, Zugaro L, Splendiani A, et al. Anaesthetics, steroids and platelet-rich plasma (PRP) in ultrasound-guided musculoskeletal procedures. BJR. 2016;89:20150355.

17. Peerbooms JC, Sluimer J, Bruijn DJ, Gosens T. Positive effect of an autologous platelet concentrate in lateral epicondylitis in a double-blind randomized controlled trial. Am J Sports Med. 2010;38:255-62.

18. Singh P, Madanipour S, Bhamra JS, Gill I. A systematic review and metaanalysis of platelet-rich plasma versus corticosteroid injections for plantar fasciopathy. Int Orthopaedics (SICOT). 2017:41:1169-81.

19. Fitzpatrick J, Bulsara MK, O'Donnell J, Zheng MH. Leucocyte-rich platelet-rich plasma treatment of gluteus medius and minimus tendinopathy: a doubleblind randomized controlled trial with 2-year follow-up. Am J Sports Med. 2019;47:1130-7.

20. Le ADK, Enweze L, DeBaun MR, Dragoo JL. Current clinical recommendations for use of platelet-rich plasma. Curr Rev Musculoskelet Med. 2018;11:624-34.

21. Redler A, Proietti L, Mazza D, Koverech G, Vadala A, De Carli A, Ferretti A. Rupture of the patellar tendon after platelet-rich plasma treatment: a case report. Clin J Sport Med. 2020;30:e20-2.

22. Ballard TNS, Kozlow JH. Trigger finger in adults. CMAJ. 2015;188:61.

23. Brinks A, Koes BW, Volkers AC, Verhaar JA, Bierma-Zeinstra SM. Adverse effects of extra-articular corticosteroid injections: a systematic review. BMC Musculoskelet Disord. 2010;11:206.

24. Bruijnzeel H, Neuhaus V, Fostvedt S, Jupiter JB, Mudgal CS, Ring DC. Adverse events of open A1 pulley release for idiopathic trigger finger. J Hand Surg. 2012;37:1650-6.

25. MacDermid JC, Turgeon T, Richards RS, Beadle M, Roth JH. Patient rating of wrist pain and disability: a reliable and valid measurement tool. J Orthop Trauma. 1998:12:577-86.

26. Sandelin H, Jalanko T, Huhtala H, Lassila H, Haapala J, Helkamaa T. Translation and validation of the Finnish version of the patient-rated wrist evaluation questionnaire (PRWE) in patients with acute distal radius fracture. Scand J Surg. 2016;105:204-10.

27. Beaton DE, Wright JG, Katz JN. Development of the QuickDASH. J Bone Joint Surg. 2005;87:1038-46.

28. Hacklin E, Timlin S, Madanat R, Strandberg N, Aro H. DASH-kyselykaavakkeen suomentaminen ja kulttuuriadaptaatio. Suomen Ortopedia ja Traumatologia. 2009;32:252-4

29. Haefeli M, Elfering M. Pain assessment. Eur Spine J. 2006;15:S17-24.

30. Massy-Westropp N, Ahern M, Krishnan J. A visual analogue scale for assessment of the impact of rheumatoid arthritis in the hand: validity and repeatability. J Hand Ther. 2005;18:30-3.

31. Kapandji A. Clinical test of apposition and counter-apposition of the thumb. Ann Chir Main. 1986:5:67-73.

32. Walenkamp MM, de Muinck Keizer RJ, Goslings JC, Vos LM, Rosenwasser MP, Schep NW. The minimum clinically important difference of the patient-rated wrist evaluation score for patients with distal radius fractures. Clin Orthop Relat Res. 2015:473:3235-41.
33. Sorensen AA, Howard D, Tan WH, Ketchersid J, Calfee RP. Minimal clinically important differences of 3 patient-rated outcomes instruments. J Hand Surg Am. 2013;38:641-9.

34. Järvinen TLN, Sihvonen R, Bhandari M, Sprague S, Malmivaara A, Paavola M, et al. Blinded interpretation of study results can feasibly and effectively diminish interpretation bias. J Clin Epidemiol. 2014;67:769-72.

35. Azur MJ, Stuart EA, Frangakis C, Leaf PJ. Multiple imputation by chained equations: what is it and how does it work? Int J Methods Psychiatr Res. 2011;20:40-9.

36. Jones I, Togashi R, Thomas Vangsness C Jr. The economics and regulation of PRP in the evolving field of orthopedic biologics. Curr Rev Musculoskelet Med. 2018;11:558-65.

37. Man D, Plosker H, Winland-Brown JE. The use of autologous platelet-rich plasma (platelet gel) and autologous platelet-poor plasma (fibrin glue) in cosmetic surgery. Plast Reconstr Surg. 2001;107:238-9.

38. Kia C, Baldino J, Bell R, Ramji A, Uyeki C, Mazzocca A. Platelet-rich plasma: review of current literature on its use for tendon and ligament pathology. Curr Rev Musculoskelet Med. 2018;11:566-72.

39. Chen $X$, Jones IA, Park C, Vangsness $C T$ Jr. The efficacy of platelet-rich plasma on tendon and ligament healing: a systematic review and metaanalysis with bias assessment. Am J Sports Med. 2017:46:2020-32.

40. Malahias MA, Roumeliotis L, Nikolaou VS, Chronopoulos E, Sourlas I, Babis GC. Platelet-rich plasma versus corticosteroid intra-articular injections for the treatment of trapeziometacarpal arthritis: a prospective randomized controlled clinical trial. Cartilage. 2018;20:1947603518805230.

41. Ramesh $R$, Jeyaraman M, Prajwal GS. The prospective study on efficacy and functional outcome of autologous platelet rich plasma injection in musculoskeletal disorders. EC Orthopaedics. 2018;9(12):849-63.

42. Shahid M, Kundra R. Platelet-rich plasma (PRP) for knee disorders. EFORT Open Rev. 2017;2:28-34

\section{Publisher's Note}

Springer Nature remains neutral with regard to jurisdictional claims in published maps and institutional affiliations.
Ready to submit your research? Choose BMC and benefit from:

- fast, convenient online submission

- thorough peer review by experienced researchers in your field

- rapid publication on acceptance

- support for research data, including large and complex data types

- gold Open Access which fosters wider collaboration and increased citations

- maximum visibility for your research: over $100 \mathrm{M}$ website views per year

At $\mathrm{BMC}$, research is always in progress.

Learn more biomedcentral.com/submission 